\title{
Feasible elimination procedures in social choice : an axiomatic characterization
}

Citation for published version (APA):

Peleg, B., \& Peters, H. J. M. (2016). Feasible elimination procedures in social choice : an axiomatic characterization. Maastricht University, Graduate School of Business and Economics. GSBE Research Memoranda No. 001 https://doi.org/10.26481/umagsb.2016001

Document status and date:

Published: 01/01/2016

DOI:

10.26481/umagsb.2016001

Document Version:

Publisher's PDF, also known as Version of record

\section{Please check the document version of this publication:}

- A submitted manuscript is the version of the article upon submission and before peer-review. There can be important differences between the submitted version and the official published version of record.

People interested in the research are advised to contact the author for the final version of the publication, or visit the DOI to the publisher's website.

- The final author version and the galley proof are versions of the publication after peer review.

- The final published version features the final layout of the paper including the volume, issue and page numbers.

Link to publication

\footnotetext{
General rights rights.

- You may freely distribute the URL identifying the publication in the public portal. please follow below link for the End User Agreement:

www.umlib.nl/taverne-license

Take down policy

If you believe that this document breaches copyright please contact us at:

repository@maastrichtuniversity.nl

providing details and we will investigate your claim.
}

Copyright and moral rights for the publications made accessible in the public portal are retained by the authors and/or other copyright owners and it is a condition of accessing publications that users recognise and abide by the legal requirements associated with these

- Users may download and print one copy of any publication from the public portal for the purpose of private study or research.

- You may not further distribute the material or use it for any profit-making activity or commercial gain

If the publication is distributed under the terms of Article $25 \mathrm{fa}$ of the Dutch Copyright Act, indicated by the "Taverne" license above, 
Bezalel Peleg, Hans Peters

Feasible elimination

procedures in social choice:

An axiomatic characterization

$\mathrm{RM} / 16 / 001$

\section{GSBE}

Maastricht University School of Business and Economics

Graduate School of Business and Economics

P.O Box 616

NL- 6200 MD Maastricht

The Netherlands 


\title{
Feasible elimination procedures in social choice: an axiomatic characterization*
}

\author{
Bezalel Peleg ${ }^{\dagger} \quad$ Hans Peters ${ }^{\ddagger}$
}

This version, December 2015

\begin{abstract}
Feasible elimination procedures (Peleg, 1978) play a central role in constructing social choice functions which have the following property: in the associated game form, for any preference profile there exists a strong Nash equilibrium resulting in the sincere outcome. In this paper we provide an axiomatic characterization of the social choice correspondence resulting from applying feasible elimination procedures. The axioms are anonymity, Maskin monotonicity, and independent blocking.
\end{abstract}

Journal of Economic Literature Classification Nos. C70, D71

Keywords Feasible elimination procedure, anonymity, Maskin monotonicity, independent blocking, axiomatization

\section{Introduction}

\section{$1.1 \quad$ Background}

We consider the classical social choice model with finitely many voters who have preferences - linear orderings - over a finite set of alternatives. A social choice function assigns an alternative to every profile of preferences, and induces an ordinal game in which every voter has the set of all preferences as strategy space, and evaluates an alternative according to his true, sincere preference. The theorem of Gibbard (1973) and Satterthwaite (1975) says that, for every social choice function with range at least three and which is nondictatorial on this range, there is a profile of sincere preferences which is not a Nash equilibrium in this game. Equivalently, such a social choice function is not strategy-proof.

\footnotetext{
${ }^{*}$ Financial support from GSBE, Maastricht University, and of The Federmann Center for the Study of Rationality, The Hebrew University of Jerusalem, is gratefully acknowledged.

${ }^{\dagger}$ The Federmann Center for the Study of Rationality and the Institute of Mathematics, The Hebrew University of Jerusalem, Jerusalem 91904, Israel. Email: pelegba@math.huji.ac.il.

${ }_{\ddagger}^{\ddagger}$ Department of Quantitative Economics, Maastricht University, Maastricht, The Netherlands. Email: h.peters@maastrichtuniversity.nl.
} 
Thus, since the only strategy-proof social choice functions are the dictatorial ones, it follows that strategy-proofness is equivalent to every profile of sincere preferences being an even strong Nash equilibrium. Peleg (1978) therefore considered the following weaker condition: for every profile of sincere preferences there exists a strong Nash equilibrium resulting in the sincere alternative, i.e., the alternative assigned if the voters report sincerely. Social choice functions having this property are called ESC (exactly and strongly consistent).

Thus, if an ESC social choice function is used, then it is at least plausible that the sincere alternative results. An additional motivation for using an ESC social choice function derives from the fact that the sincere preference profile is not manipulable in the following sense. Suppose a coalition deviates, by not reporting sincerely, such that all its members are better off by this deviation. Then there is a deviation by the complement of that coalition such that at least one member of the originally deviating coalition is not better off compared to the sincere profile. In other words, by deviating from the sincere profile no coalition can guarantee (i.e., independent of the outside agents) to make all its members better off. See Peleg and Procaccia (2007), Peleg and Peters (2010, Sect. 8.5), and in a related context Peleg and Peters (2015). In still other words, ESC social choice functions not only admit a strong Nash equilibrium resulting in the sincere outcome but also make sincere voting itself a safe strategy for voters and coalitions in situations where it is difficult to predict how others will vote.

\subsection{Motivation and objective}

ESC social choice functions can be obtained by selecting alternatives resulting from so-called feasible elimination procedures, introduced in Peleg (1978). A fortiori, using feasible elimination procedures is the only way to construct ESC social choice functions under three conditions, namely: the number of voters is greater than or equal to the number of alternatives minus one, the social choice function is anonymous, and it satisfies no veto power. The last condition says that no single agent can exclude any alternative from being chosen. See Peleg and Peters (2010), Sect. 10.5, which in turn is based on Holzman (1986). These conditions are natural and thus, feasible elimination procedures are essential for achieving this particular way of alleviating the consequences of the GibbardSatterthwaite Theorem.

Feasible elimination procedures work as follows. Attach weights (natural numbers) to the alternatives such that the sum of these weights is equal to the number of voters plus one. Consider a preference profile and delete an alternative $x$ that is bottom ranked by at least as many voters as the weight of $x$; also delete as many preferences from the profile, having $x$ bottom ranked, as the weight of $x$. Repeat this procedure for the reduced profile, until one alternative is left. This alternative is called 'maximal' for the preference profile under consideration. It does not have to be unique.

The objective of this paper is to provide an axiomatic characterization of the social choice correspondence assigning the maximal alternatives to each prefer- 
ence profile. The axioms that we use are two general conditions: anonymity and Maskin monotonicity; and a condition related to the blocking power of coalitions. Anonymity is clear, and Maskin monotonicity (Maskin, 1999) says that if the position of a chosen alternative improves in the preference profile, then it will still be chosen in the new profile. Maskin monotonicity is well-known as a necessary condition for implementation.

A coalition can block a set of alternatives if by putting this set at the bottom part of their preferences no assigned alternative will be in this set, whatever the reported preferences of the outside voters. A coalition minimally blocks such a set if no proper subcoalition can block it. The condition related to the blocking power of coalitions is called 'independent blocking'. Its main implication is that if two disjoint sets of alternatives are minimally blocked by two disjoint coalitions, then the union of the two sets of alternatives is minimally blocked by the union of those coalitions. The main result of the paper is that the axioms of anonymity, Maskin monotonicity, and independent blocking characterize the social choice correspondence assigning the maximal alternatives, i.e., the alternatives resulting from feasible elimination procedures. We also show that these axioms are logically independent.

Section 2 presents preliminaries, and in Section 3 we state and prove the characterization result. Section 4 concludes.

Notations The following basic notations are used throughout. For a set $D,|D|$ denotes the cardinality of $D, P(D)$ the power set, i.e., the set of all subsets of $D$, and $P_{0}(D)$ the set of all nonempty subsets of $D$.

\section{Preliminaries}

Let $A$ be the set of $m$ alternatives, $m \geq 2$, and let $N=\{1, \ldots, n\}, n \geq 2$, be the set of voters. Subsets of $N$ are called coalitions. Let $L$ be the set of all preferences, i.e., complete, antisymmetric and transitive binary relations, on $A$. Then $L^{N}$ is the set of all (preference) profiles. A social choice correspondence (SCC) is a function $H: L^{N} \rightarrow P_{0}(A)$.

The main SCC of interest in this paper is based on so-called feasible elimination procedures. Informally, first, attach weights $\beta(x) \in \mathbb{N}$ to the alternatives $x \in A$. Consider a preference profile and take an alternative $x$ that is bottom ranked at least $\beta(x)$ times. Delete that alternative from the profile and at the same time delete $\beta(x)$ preferences where $x$ is bottom ranked. Repeat this procedure until one alternative remains, which happens under appropriate conditions.

Formally, we have the following definition.

Definition 2.1. Assume that $n+1 \geq m$ and let $\beta: A \rightarrow \mathbb{N}$ satisfy $\sum_{x \in A} \beta(x)=$ $n+1$. Let $R^{N} \in L^{N}$. A feasible elimination procedure (f.e.p.) for $R^{N}$ is a sequence $\left(x_{1}, C_{1} ; \ldots ; x_{m-1}, C_{m-1} ; x_{m}\right)$ such that

1) $A=\left\{x_{1}, \ldots, x_{m}\right\}$, 
2) $C_{1}, \ldots, C_{m-1}$ are pairwise disjoint subsets of $N$ and $\left|C_{j}\right|=\beta\left(x_{j}\right)$ for all $j=1, \ldots, m-1$,

3) $x_{k} R^{i} x_{j}$ for all $j=1, \ldots, m-1, k=j+1, \ldots, m$, and $i \in C_{j}$.

It is not difficult to see that there exists always at least one f.e.p. under the assumptions in the definition. Henceforth in this paper we assume $n+1 \geq m$. An alternative $x$ is $R^{N}$ - maximal if there exists an f.e.p. $\left(x_{1}, C_{1} ; \ldots ; x_{m-1}, C_{m-1} ; x\right)$. We denote

$$
M_{\beta}\left(R^{N}\right)=\left\{x \in A: x \text { is } R^{N} \text {-maximal }\right\} .
$$

Thus, $M_{\beta}$ depends on the exogenously chosen weights $\beta(x), x \in A$, which can be varied as long as $\sum_{x \in A} \beta(x)=n+1$. Note that it is not always possible to choose all weights equal, so it is not always possible to achieve neutrality.

The importance of the SCC $M_{\beta}$ derives from the fact that every selection from it produces an ESC social choice function, and that under some additional but natural conditions, selecting from $M_{\beta}$ for some weight function $\beta$ is the only way to achieve ESC social choice functions. We refer to the Introduction of the paper for more explanation.

\section{Axiomatic characterization of $M$}

Let $H$ be an SCC. We first introduce some terminology and notations concerning the blocking power of coalitions.

A coalition $S \in P_{0}(N)$ blocks a set $B \in P_{0}(A)$ at $H$ if for any profile $Q^{S} \in L^{S}$ for $S$ such that $x Q^{i} y$ for each $x \in A \backslash B$ and $y \in B$, we have $H\left(Q^{S}, R^{N \backslash S}\right) \subseteq A \backslash B$ for all $R^{N \backslash S} \in L^{N \backslash S}$. Coalition $S \in P_{0}(N)$ minimally blocks $B$ at $H$ if no proper nonempty subcoalition of $S$ blocks $B$ at $H$. If a set $B \in P_{0}(A)$ is blocked by some coalition at $H$, then we define the blocking coefficient $b_{H}(B)$ as the minimal size of such a coalition, hence

$$
b_{H}(B)=\min \left\{|S|: S \in P_{0}(N) \text { blocks } B \text { at } H\right\} .
$$

Otherwise, we define $b_{H}(B)=n+1$. Note that, since $H\left(R^{N}\right) \neq \emptyset$ for all $R^{N} \in L^{N}$ by definition, no coalition blocks $A$, and thus $b_{H}(A)=n+1$ always. The choice of blocking coefficient $n+1$ for an unblocked set of alternatives will have some consequences under the last axiom below, see also Remark 3.1. We call $b_{H}: P_{0}(A) \rightarrow\{1, \ldots, n+1\}$ the blocking function of $H$.

We consider the following axioms on $H$.

Anonymity For all $R^{N} \in L^{N}$ and for all permutations $\pi$ of $N, H\left(R^{1}, \ldots\right.$, $\left.R^{n}\right)=H\left(R^{\pi(1)}, \ldots, R^{\pi(n)}\right)$.

Maskin monotonicity For all $R^{N}=\left(R^{1}, \ldots, R^{n}\right), Q^{N}=\left(Q^{1}, \ldots, Q^{n}\right) \in L^{N}$, and $x \in H\left(Q^{N}\right)$, if $x Q^{i} y$ implies $x R^{i} y$ for all $y \in A$ and $i \in N$, then $x \in H\left(R^{N}\right)$.

Independent blocking The blocking function $b_{H}$ is additive, i.e., $b_{H}\left(B_{1} \cup\right.$ $\left.B_{2}\right)=b_{H}\left(B_{1}\right)+b_{H}\left(B_{2}\right)$ for all $B_{1}, B_{2} \in P_{0}(A)$ with $B_{1} \cap B_{2}=\emptyset$. 
Anonymity needs no further explanation. Maskin monotonicity says that if a chosen alternative does not gets worse in any one's preference, then it remains to be chosen. It is a necessary condition for implementation in Nash equilibrium (Maskin, 1999).

Under anonymity, independent blocking implies for instance that if $S_{1}$ minimally blocks $B_{1}$ and $S_{2}$ minimally blocks $B_{2}$, and $S_{1}$ and $S_{2}$ as well as $B_{1}$ and $B_{2}$ are disjoint, then $S_{1} \cup S_{2}$ minimally blocks $B_{1} \cup B_{2}$.

Remark 3.1. By the choice $b_{H}(A)=n+1$, independent blocking implies the equivalence $b_{H}(B)=n+1 \Leftrightarrow B=A$. It also implies that $H$ is non-imposed, i.e., for every $a \in A$ there is a profile $R^{N} \in L^{N}$ such that $H\left(R^{N}\right)=\{a\}$. This can be seen as follows. Suppose that there is some $a \in A$ such that $H\left(R^{N}\right) \neq\{a\}$ for all $R^{N} \in L^{N}$. Then $b_{H}(A \backslash\{a\})=n+1$, so independent blocking implies $b_{H}(\{a\})=b_{H}(A)-b_{H}(A \backslash\{a\})=0$, a contradiction.

The following theorem is the announced characterization of the social choice correspondences $M_{\beta}$.

Theorem 3.2. Let $n+1 \geq m$ and let $H$ be an SCC. The following statements are equivalent.

(i) H satisfies anonymity, Maskin monotonicity, and independent blocking.

(ii) There is a function $\beta: A \rightarrow \mathbb{N}$ with $\sum_{x \in A} \beta(x)=n+1$ such that $H=M_{\beta}$.

In what follows we use the notation $\beta(B)$ for $\sum_{x \in B} \beta(x)$, where $B \in P_{0}(A)$. In the proof of Theorem 3.2 we use the following lemmas.

Lemma 3.3. Let $n+1 \geq m$ and let $\beta: A \rightarrow \mathbb{N}$ such that $\sum_{x \in A} \beta(x)=n+1$. Let $B \in P_{0}(A)$ and $S \in \bar{P}_{0}(N)$. Then $S$ minimally blocks $B$ at $M_{\beta}$ if and only if $|S|=\beta(B)$.

Proof. For the only-if statement, suppose that $S$ minimally blocks $B$ at $M_{\beta}$. Let $Q^{S} \in L^{S}$ such that $x Q^{i} y$ for all $i \in S, x \in A \backslash B$ and $y \in B$. Then $M_{\beta}\left(Q^{S}, R^{N \backslash S}\right) \subseteq A \backslash B$ for all $R^{N \backslash S} \in L^{N \backslash S}$. Consider, in particular, a profile $\widetilde{R}^{N \backslash S}$ such that $x \widetilde{R}^{i} y$ for all $x \in B, y \in A \backslash B$, and $i \in N \backslash S$. For an f.e.p. $\left(x_{1}, C_{1} ; \ldots ; x_{m-1}, C_{m-1} ; x_{m}\right)$ for $\left(Q^{S}, \widetilde{R}^{N \backslash S}\right)$ we have $x_{m} \in M_{\beta}\left(Q^{S}, \widetilde{R}^{N \backslash S}\right) \subseteq$ $A \backslash B$ and therefore $B \subseteq\left\{x_{1}, \ldots, x_{m-1}\right\}$. By definition of $\widetilde{R}^{N \backslash S}$ we must have $C_{j} \subseteq S$ for every $j \in\{1, \ldots, m-1\}$ with $x_{j} \in B$. Therefore, $|S| \geq$ $\sum_{j \in\{1, \ldots, m-1\}: x_{j} \in B}\left|C_{j}\right|=\beta(B)$. Now consider any coalition $T \subseteq S$ such that $|T|=\beta(B)$ and a profile $P^{T} \in L^{T}$ such that $x P^{i} y$ for all $x \in A \backslash B$ and $y \in B$. Then $|N \backslash T|=n-\beta(B)=\beta(A \backslash B)-1<\beta(A \backslash B)$, so that any f.e.p. for any $\left(P^{T}, R^{N \backslash T}\right)$ results in an alternative of $A \backslash B$. Hence, $T$ blocks $B$ at $M_{\beta}$, so that $T=S$ by minimality of $S$. Hence, $|S|=\beta(B)$.

For the if-statement, if $|S|=\beta(B)$ then by the preceding argument $S$ blocks $B$ at $M_{\beta}$. For any $T \subseteq S$ to block $B$ we need $|T| \geq \beta(B)$ by the same argument as in the first part of the proof. Hence, $S$ minimally blocks $B$ at $M_{\beta}$.

The next lemma is crucial for proving the implication $(i) \Rightarrow(i i)$ in Theorem 3.2. It is a reformulation of an existing result. 
Lemma 3.4. Let $n+1 \geq m$ and let $\beta: A \rightarrow \mathbb{N}$ such that $\sum_{x \in A} \beta(x)=n+1$. Let $x \in A$ and $R^{N} \in L^{N}$. The following statements are equivalent.

(i) $x \in M_{\beta}\left(R^{N}\right)$.

(ii) There are no $S \in P_{0}(N)$ and $B \in P_{0}(A)$ such that $|S| \geq \beta(A \backslash B)$, $x \in A \backslash B$, and $y R^{i} x$ for all $i \in S$ and $y \in B$.

Proof. This is Theorem 9.3.6 in Peleg and Peters (2010).

We are now sufficiently equipped to prove the main result of the paper.

Proof of Theorem 3.2. We first prove the implication $(i i) \Rightarrow(i)$.

Let $\beta: A \rightarrow \mathbb{N}$ such that $\sum_{x \in A} \beta(x)=n+1$. Clearly, $M_{\beta}$ is anonymous. For Maskin monotonicity of $M_{\beta}$, see Remark 9.3.7 in Peleg and Peters (2010). From Lemma 3.3 it follows that the blocking function $b=b_{M_{\beta}}$ of $M_{\beta}$ is $\beta$, i.e., $b(B)=\beta(B)$ for all $B \in P_{0}(A)$, and independent blocking follows since $\beta$ is additive.

For the implication $(i) \Rightarrow($ ii $)$, let $H$ satisfy the three axioms. Define $\beta: A \rightarrow$ $\mathbb{N}$ by $\beta(x)=b_{H}(x)$ for all $x \in A$. Then by independent blocking, $\sum_{x \in A} \beta(x)=$ $n+1$, so $M_{\beta}$ is well-defined. We prove that $H=M_{\beta}$. Let $R^{N} \in L^{N}$.

First, let $x \in M_{\beta}\left(R^{N}\right)$. Then there exists an f.e.p. $\left(x_{1}, C_{1} ; \ldots ; x_{m-1}, C_{m-1}\right.$; $x)$ with respect to $R^{N}$. Let now $Q^{N}$ be the profile that is obtained from $R^{N}$ by lowering $x_{j}$ to the bottom of $R^{i}$ for all $i \in C_{j}$ and for $j=1, \ldots, m-1$, and leaving everything else intact. By the definition of blocking coefficients, $H\left(Q^{N}\right) \subseteq A \backslash\left\{x_{j}\right\}$ for all $j=1, \ldots, m-1$, so that $H\left(Q^{N}\right)=\{x\}$. Finally, since $x R^{i} x_{j}$ for all $i \in C_{j}$ and $j=1, \ldots, m-1$ (by the third condition in Definition 2.1), and since $H$ is Maskin monotonic, $x \in H\left(R^{N}\right)$.

Second, let $x \in H\left(R^{N}\right)$. Suppose there are $S \in P_{0}(N)$ and $B \in P_{0}(A)$ as in (ii) of Lemma 3.4, i.e., $|S| \geq \beta(A \backslash B), x \in A \backslash B$, and $y R^{i} x$ for all $y \in B$. For each $i \in S$ let $Q^{i} \in L$ be a preference with $y Q^{i} z \Leftrightarrow y R^{i} z$ for all $y, z \in A \backslash B$ and with $y Q^{i} z$ for all $y \in B$ and $z \in A \backslash B$. Since $|S| \geq \beta(A \backslash B)=b_{H}(A \backslash B)$, by anonymity we have that $S$ blocks $A \backslash B$ at $H$, so that $x \notin H\left(Q^{S}, R^{N \backslash S}\right)$. On the other hand, since $x \in H\left(R^{N}\right)$ and $y R^{i} x$ for all $i \in S$ and $y \in B$, Maskin monotonicity of $H$ implies $x \in H\left(Q^{S}, R^{N \backslash S}\right)$, a contradiction. Hence, $x \in M_{\beta}\left(R^{N}\right)$ by Lemma 3.4 .

We finally show that the three axioms in Theorem 3.2 are logically independent, by exhibiting three examples.

Example 3.5. Let $A=\{x, y\}$ and let $N=\{1,2,3,4\}$. Define the SCC $H$ as follows. Let $R^{N} \in L^{N}$. If $R^{1}=R^{2}=y x$ (i.e., both 1 and 2 prefer $y$ above $x$ ) then $H\left(R^{N}\right)=\{y\}$. If $R^{2}=R^{3}=R^{4}=x y$ then $H\left(R^{N}\right)=\{x\}$. In all other cases, $H\left(R^{N}\right)=\{x, y\}$. Then $H$ is Maskin monotonic and independently blocking: $b_{H}(x)+b_{H}(y)=3+2=5=b_{H}(A)$. However, $H$ is not anonymous.

Example 3.6. It is not difficult to see that there exist anonymous selections from $M_{\beta}$ : e.g., take $Q \in L$ and let $F\left(R^{N}\right)$ be the alternative of $M_{\beta}\left(R^{N}\right)$ that is maximal according to $Q$. Such a selection is still independently blocking. 
However, it cannot be Maskin monotonic (if $m \geq 3$ ) because then by Muller and Satterthwaite (1977) it would be dictatorial.

Example 3.7. The Pareto correspondence $P$ assigns to each profile $R^{N}$ the set $\left\{x \in A\right.$ : there is no $y \in A$ with $y P^{i} x$ for all $\left.i \in N\right\}$. It is anonymous and Maskin monotonic, but it is not independently blocking: $b_{P}(B)=n$ for every $B \in P_{0}(A), B \neq A$.

\section{Conclusion}

For any sincere preference profile, in the game associated with an exactly and strongly consistent social choice function there exists always a strong Nash equilibrium resulting in the sincere outcome. Also, for such a social choice function, sincere voting itself is a safe strategy in the sense that a coalition deviating from it is not guaranteed a better outcome. In order to construct exactly and strongly consistent social choice functions feasible elimination procedures play a central role. In this paper, we have provided an axiomatic characterization of the social choice correspondence that assigns maximal alternatives, i.e., alternatives resulting from feasible elimination procedures. The proof of our axiomatic characterization depends to an important extent on earlier results, in particular on Theorem 9.3.6 in Peleg and Peters (2010), which, in turn, goes back to an unpublished result of Polishchuk (1978). This theorem is phrased in terms of an effectivity function and its core.

\section{References}

Gibbard A (1973) Manipulation of voting schemes: A general result. Econometrica 41:587-602

Holzman R (1986) On strong representations of games by social choice functions. Journal of Mathematical Economics 15:39-57

Maskin E (1999) Nash equilibrium and welfare optimality. The Review of Economic Studies 66:23-38

Muller E, Satterthwaite MA (1977) The equivalence of strong positive association and strategy-proofness. Journal of Economic Theory 14:412-418

Peleg B (1978) Consistent voting systems. Econometrica 46:153-161

Peleg B, Peters H (2010) Strategic Social Choice. Springer, Berlin

Peleg B, Peters H (2015) Choosing $k$ from $m$ : feasible elimination procedures reconsidered. Working Paper, Maastricht University, The Netherlands

Peleg B, Procaccia AD (2007) Mediators enable truthful voting. DP 451, Center for the Study of Rationality, The Hebrew University of Jerusalem 
Polishchuk I (1978) Monotonicity and uniqueness of consistent voting systems. Center for Research in Mathematical Economics and Game Theory, Hebrew University of Jerusalem

Satterthwaite MA (1975) Strategy-proofness and Arrow's conditions: Existence and correspondence theorems for voting procedures and social welfare functions. Journal of Economic Theory 10:187-207 